\title{
Challenges in Managing Massive Neck Pseudoaneurysm
}

\author{
Bharath $V^{1, \odot}$ Sumit Agasty ${ }^{1} \quad$ Milind Padmakar Hote ${ }^{1}$ \\ ${ }^{1}$ Department of Cardiothoracic and Vascular Surgery, All India \\ Address for correspondence Bharath V, MCh, Department of \\ Institute of Medical Sciences, New Delhi, India52160162 \\ Cardiothoracic and Vascular Surgery, All India Institute of Medical \\ Sciences, New Delhi, India (e-mail: drbharathv@gmail.com).
}

\author{
Abstract \\ Keywords \\ - Carotid artery \\ pseudoaneurysm \\ - Ruptured \\ pseudoaneurysm \\ - Mycotic \\ pseudoaneurysm
}

Pseudoaneurysms in the neck are challenging surgical cases. They need detailed preoperative evaluation, treatment of etiology, and surgical/interventional management at appropriate time.

Here, we describe a case of 45 -year-old female who presented to emergency with impending rupture of swelling in the right side of neck. On evaluation, it was found to be a pseudoaneurysm of right common carotid artery (RCCA). She was planned for emergency surgery, but the swelling ruptured before the patient could be taken into the operation room (OR). The challenges faced in managing it are described below.

\section{Introduction}

Pseudoaneurysm is a false aneurysm, as it does not have all the layers of arterial wall. ${ }^{1}$ It can be of spontaneous, infective, traumatic, or neoplastic etiology. ${ }^{2}$ Pseudoaneurysms in the neck present early with obvious swelling and can have the following symptoms: disfigurement, change in voice, difficulty in swelling, and limited neck mobility.

Their workup includes detailed history regarding identification of etiology, examination and relevant investigations. CT provides information regarding precise anatomical location, extent, feeding artery and compression of other structures. $\mathrm{CT}$ also helps in preoperative planning and decision-making.

The management of pseudoaneurysm includes treatment of etiology, surgical intervention for pseudoaneurysm, and prevention of complications. ${ }^{3,4}$

\section{Case Report}

A 45-year-old female presented to emergency with large swelling in right side of neck, which was present for 1 year but had rapidly increased in size since the past few days. She also complained of heaviness in voice, difficulty in swallowing solids, and difficulty in turning neck to right side. She was diagnosed with pulmonary tuberculosis 6 months ago and had been on antitubercular drugs, but she did not complete treatment. There was no history of trauma, stridor, neurological symptoms, or any past history of malignancy.

On examination, there was a large $14 \times 12 \mathrm{~cm}$ swelling on right side of neck, which was extending from angle of mandible to clavicle, from midline anteriorly and reaching trapezius border posteriorly. Multiple areas of pressure necrosis on skin were present. The swelling was nonpulsatile. Superficial temporal and right upper limb arterial pulsations were normal ( - Fig. 1).

The patient underwent $\mathrm{CT}$ angiography which showed pseudoaneurysm of size $12 \times 6 \mathrm{~cm}$ arising from the proximal third of RCCA. There was contrast enhancement of the pseudoaneurysm sac with perianeurysmal fat stranding and enlarged paratracheal and cervical lymph nodes (-Fig. 2 ). published online August 4, 2021
DOI https://doi.org/ 10.1055/s-0041-1732845 ISSN 2457-0206 (c) 2021. Official Publication of The Simulation Society (TSS), accredited by International Society of Cardiovascular Ultrasound (ISCU).

This is an open access article published by Thieme under the terms of the Creative Commons Attribution-NonDerivative-NonCommercial-License, permitting copying and reproduction so long as the original work is given appropriate credit. Contents may not be used for commercial purposes, or adapted, remixed, transformed or built upon. (https://creativecommons.org/licenses/by-nc-nd/4.0/). Thieme Medical and Scientific Publishers Pvt. Ltd. A-12, 2nd Floor, Sector 2, Noida-201301 UP, India 


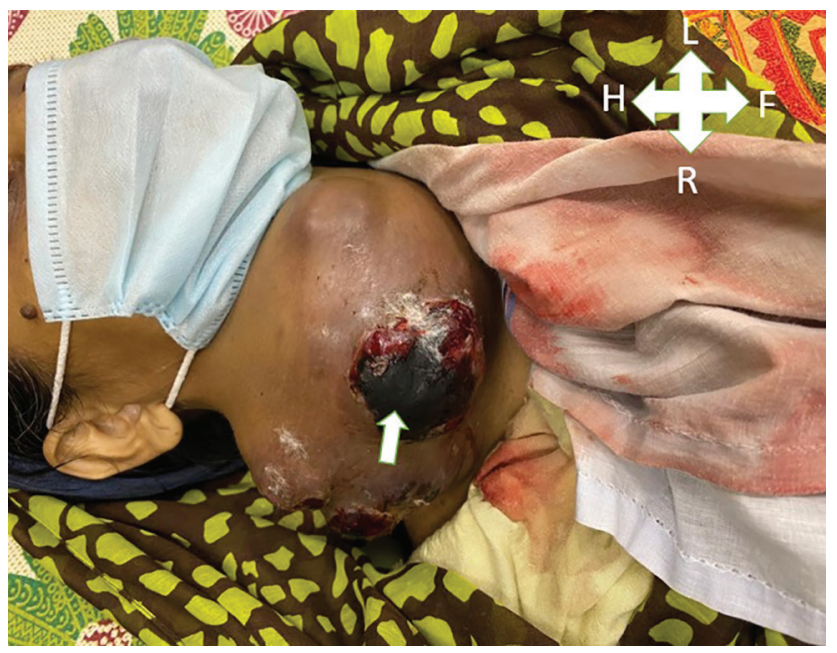

Fig. 1 External appearance of the pseudoaneurysm in the right side of neck. Arrow indicates site of pressure necrosis due to rapid increase in size of pseudoaneurysm.

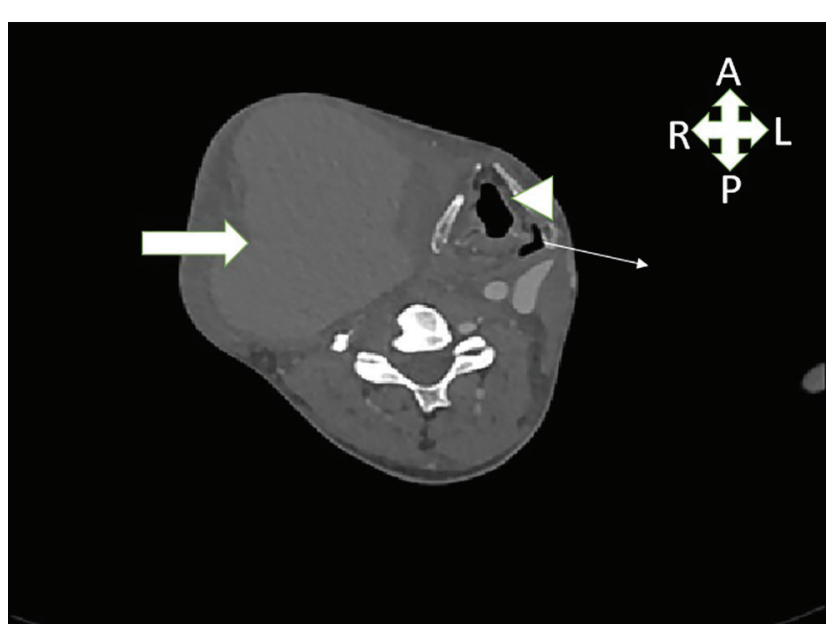

Fig. 2 Contrast CT image of neck showing pseudoaneurysm and its relation to surrounding structures. Block arrow-pseudoaneurysm; arrowhead-trachea; line arrow-esophagus.

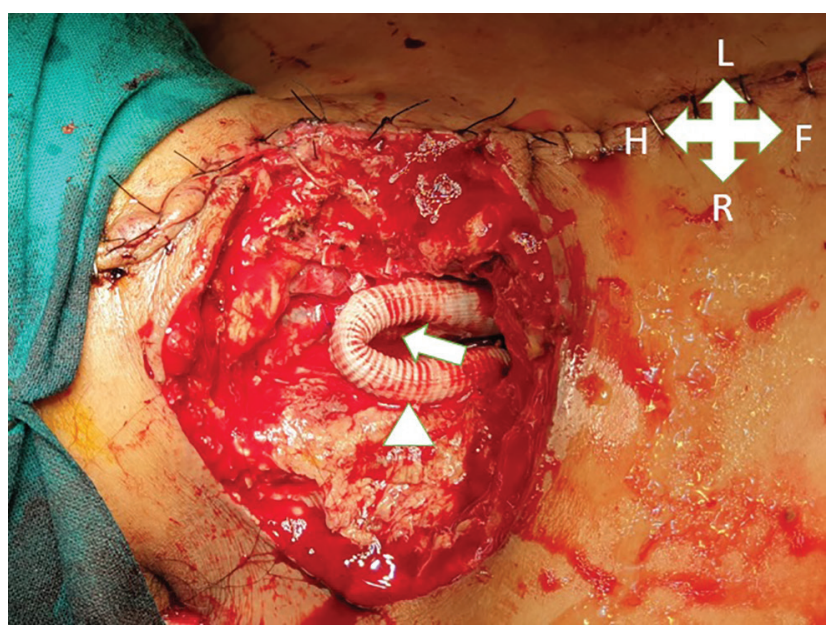

Fig. 3 Operative image showing dacron Y graft anastomosed to right subclavian artery (RSCA) (arrowhead) and right common carotid artery (RCCA) (arrow) from ascending aorta, postpseudoaneurysm excision.

\section{Treatment Options}

Possibility of endovascular intervention was considered but was rejected due to suspicion of active tuberculosis and presence of infected, necrotic tissues all around.

The anticipated problems with surgical approach were obtaining proximal and distal vascular control. The possibility of using cardiopulmonary bypass ( $\mathrm{CPB}$ ) and sternotomy for proximal control were considered.

Informed written consent was taken, cross-matched blood arranged, and parts prepared. Before the patient could be shifted to operation room (OR), her pseudoaneurysm ruptured, and she started bleeding profusely. Compression was applied over the site while fluid resuscitation was started and patient shifted to OR.

\section{Operative Challenge}

The goals of surgery were to stop any further bleeding, repair the rent in RCCA, and achieve satisfactory wound cover.

Before surgery, emergency intubation was done, and basic monitoring instituted like near infrared spectroscopy (NIRS).

To conserve blood and to prevent exsanguination, a decision was made to go through emergency $\mathrm{CPB}$ via femoral vessels. Once on $\mathrm{CPB}$, cooling was done to $20{ }^{\circ} \mathrm{C}$ for deep hypothermic circulatory arrest (DHCA). Midline sternotomy was done, and right brachiocephalic artery was dissected and looped.

When the core temperature reached $20^{\circ} \mathrm{C}$, right brachiocephalic artery was clamped and CPB flows reduced to minimal. The pseudoaneurysm was opened, and the clots and hematoma in adjoining tissues were evacuated. Few fibers of right sternocleidomastoid muscle had pressure necrosis which were excised. Rent was then identified in the proximal third of RCCA near the right brachiocephalic bifurcation. Due to unhealthy surrounding structures and vessels, a decision was made to bypass the disease segment of proximal right carotid and right subclavian artery (RSCA). As two vessels needed to be bypassed, and it was an emergency setting, a dacron Y graft was chosen instead of autologous radial or femoral artery.

A side biting clamp was applied on ascending aorta and 16/8/8 dacron $Y$ graft was anastomosed to ascending aorta. The two $8 \mathrm{~mm}$ arms were then anastomosed to distal RCCA and RSCA ( - Fig. 3 ). The graft was deaired and full CPB flows was resumed, and rewarming was started.

Patient was then weaned off from СРB after complete rewarming to $36^{\circ} \mathrm{C}$.

As the skin defect was large, plastic surgery opinion was sought. They performed pectoralis major musculocutaneous flap cover of defect in right neck on postoperative day (POD) 1 .

\section{Postoperative Course}

Patient had left hemiplegia detected after becoming awake on POD 1. The weakness in the left lower limb improved on the next day (POD 2). Left upper limb weakness gradually improved over the next 3 weeks. 


\section{Discussion and Conclusion}

Pseudoaneurysm of neck vessels are a group of challenging surgical entities. They carry high risk to life and cerebral hypoperfusion. Several groups have advocated usage of autologous femoral and radial artery in reconstruction of common carotid artery. ${ }^{5}$ Endovascular interventions are being increasing used in the management of neck pseudoaneurysm. The aim of any treatment modality will be to protect cerebral perfusion, prevent pseudoaneurysm rupture, and correct etiology.

\section{Funding}

None

\section{Ethics Approval}

N/A

\section{Consent for publication}

Taken.

\section{Conflicts of interest/Competing interest}

None declared.

\section{References}

1 Kenyon O, Tanna R, Sharma V, Kullar P. Mycotic pseudoaneurysm of the common carotid artery: an unusual neck lump. BMJ Case Rep 2020;13(11):e239921

2 Pecoraro F, Dinoto E, Pakeliani D, La Rosa G, Corte G, Bajardi G. Spontaneous symptomatic common carotid artery pseudoaneurysm: case report and literature review. Ann Vasc Surg 2015;29(4):837.e9-837.e12

3 Arima D, Suematsu Y, Kurahashi K, Kaneko H, Nishi S, Yoshimoto A. Total debranching thoracic endovascular aortic repair with elephant trunk insertion technique. J Vasc Surg Cases Innov Tech 2020;6(4):626-628

4 Prince JM, Gupta N, Kartis T, Tabrizi MB, Rosenthal MG. Management of a pseudoaneurysm of the left common carotid artery origin due to blunt trauma. J Trauma Acute Care Surg 2020;89(6):e167-e169

5 Matano F, Suzuki M, Mizunari T, Yamada T, Murai Y, Morita A. Radial artery graft for giant common carotid artery pseudoaneurysm after carotid artery stenting. World Neurosurg 2020;139:401-404 